\title{
Deficiency of the Chemotactic Factor Inactivator in Human Sera with $\alpha_{1}$-Antitrypsin Deficiency
}

\author{
Peter A. Ward and Richard C. Talamo \\ From the Department of Pathology, The University of Connecticut Health \\ Center, Farmington, Connecticut 06032 and the Immunology Unit, \\ Children's Service, Massachusetts General Hospital, \\ Boston, Massachusetts 02114
}

A в S T R A C T As revealed by appropriate fractionation procedures, human serum deficient in $\alpha_{1-\text { antitrypsin }}\left(\alpha_{1-}\right.$ AT) is also deficient in the naturally occurring chemotactic factor inactivator. These serum donors had severe pulmonary emphysema. Serum from patients with clinically similar pulmonary disease, but with presence of $\alpha_{1-}$ AT in the serum, showed no such deficiency of the chemotactic factor inactivator. When normal human serum and $\alpha_{1}$-AT-deficient human sera are chemotactically activated by incubation with immune precipitates, substantially more chemotactic activity is generated in $\alpha_{1-}$ AT-deficient serum. These data indicate that in $\alpha_{1-}$ AT-deficient serum there is an imbalance in the generation and control of chemotactic factors. It is suggested that the theory regarding development of pulmonary emphysema in patients lacking the $\alpha_{1}$-antitrypsin in their serum should be modified to take into account a deficiency of the chemotactic factor inactivator.

\section{INTRODUCTION}

The $\alpha$-globulins of human serum contain several protease inhibitors: $\alpha_{1}$-antitrypsin $\left(\alpha_{1}-\mathrm{AT}\right){ }^{1}{ }^{1} \alpha_{1}$-antichymotrypsin, inter- $\alpha$ trypsin inhibitor, and $\alpha_{2}$-macroglobulin. The $\alpha_{1-}$ AT is the major trypsin inhibitor, but can also inhibit bacterial enzymes (1), the neutral protease and elastase (2-4) derived from lysosomal granules of neutrophilic granulocytes, skin collagenase (5), plasmin (6), and thrombin (4). Each of these inhibitors interacts in what appears to be a stoichiometric manner with the target enzyme binding with it and leading to its inactivation. A second type of inhibitor has been described in the $\alpha$-globulins of human serum: a carboxypeptidase B-like

Received for publication 25 August 1972 and in revised form 17 November 1972.

${ }_{1}$ Abbreviations used in this paper: $\alpha_{1}-\mathrm{AT}, \alpha_{1}$ antitrypsin; BSA, bovine serum albumin. enzyme that inactivates two classes of biologically active peptides: the kinins generated by kallikrein (7) and the anaphylatoxins that emanate as cleavage products from the third and fifth components of complement (8). Because of the ability of the carboxypeptidase B-like enzyme to inactivate the anaphylatoxins, it has been termed the anaphylatoxin inactivator (9). Recently another inactivator has been isolated from the $\alpha$-globulin region of human serum: the chemotactic factor inactivator (10). This inhibitor appears to act in an enzymatic-like fashion to inactivate complement-derived and complement-independent chemotactic factors.

This paper will record the observation that sera deficient in the $\alpha_{1}$ antitrypsin are also deficient in the chemotactic factor inactivator. This finding may bear on the mechanisms responsible for development of pulmonary emphysema in patients who have severe $\alpha_{1}$ antitrypsin deficiency.

\section{METHODS}

Sera. Five different human sera lacking $>80 \%$ of the $\alpha_{1}-\mathrm{AT}$ as judged by measurements of trypsin inhibitory capacity and $\alpha_{1}-\mathrm{AT}$ concentration (11) were used in these studies. By convention, the genotyping of these sera is PiZZ (12). In addition, one serum was used (An) from an individual with no detectable $\alpha_{1}$-AT. Each of these patients has severe, chronic pulmonary emphysema and is seriously ill. In order to determine whether the clinical condition of severe pulmonary emphysema is directly related to the status of the chemotactic factor inactivator in serum, sera from six different patients with chronic, progressive pulmonary emphysema were also studied. In each of these sera the level of $\alpha_{1}$-AT was at least $50 \%$ of the level in normal control serum. Sera from five normal humans, containing $>50 \%$ the normal levels of the $\alpha_{1}$ antitrypsin, were also used. Some of these preparations were generously provided as fresh frozen sera by Dr. Chester Alper.

Chemotaxis. Modified Boyden chambers employing micropore filters of $650 \mathrm{~nm}$ pore size were used for chemotaxis assays (13). The indicator cells were rabbit neutrophilic 
granulocytes obtained from a $4 \mathrm{~h}$ glycogen-induced peritoneal exudate. Cells were suspended in $0.1 \%$ bovine serum albumin (BSA) in Hank's medium. Chemotactic factors were diluted in the same medium. Chemotactic values reflect the numbers of migrated neutrophils in a filter, in five high power fields. Details of this technique are given elsewhere (14). In the first part of this study culture filtrates from a 24 h growth of Escherichia coli in medium 199 were used as the source of chemotactic factor (15). An amount of $50 \mu \mathrm{l}$ of this material was mixed with $20 \mu \mathrm{l}$ Hanks medium or $20 \mu \mathrm{l}$ chemotactic factor inactivator (see below for details of preparation), incubated for $20 \mathrm{~min}$ at $20^{\circ} \mathrm{C}$, then diluted to $1.0 \mathrm{ml}$ in Hanks medium for chemotactic assay.

In the other experiments serum $(0.1 \mathrm{ml})$ was chemotactically activated with immune precipitates. The source of the precipitate was $40 \mu \mathrm{g}$ antibody nitrogen (determined by quantitative precipitin analysis) with antigen (BSA) added at equivalence $(8 \mu \mathrm{g}$ albumin nitrogen). The antibody was isolated as the IgG fraction of serum from hyperimmunized rabbits (16). Chemotactic activation of sera was carried out by incubation of serum with immune precipitates at $37^{\circ} \mathrm{C}$ for $\frac{1}{2} \mathrm{~h}$. Dilutions in Hanks medium were then made for chemotactic testing.

Preparation of chemotactic factor inactivator. Serum was fractionated at room temperature with ammonium sul-

TABLE I

Inhibition of Bacterial Chemotactic Factor by Human Serum Factor

\begin{tabular}{ccc}
\hline Serum tested* & $\begin{array}{c}\text { Chemotactic } \\
\text { activity }\end{array}$ & Inhibition \\
\hline \multicolumn{1}{c}{$\alpha_{1}$-AT-sufficient (normal controls) } & $\%$ \\
1 & 45 & 70 \\
2 & 20 & 87 \\
3 & 40 & 73 \\
4 & 45 & 70 \\
none (reference & 150 & - \\
positive control) & & \\
$\alpha_{1}$-AT-deficient (patients with emphysema) \\
Bo & 130 & 13 \\
Ba & 120 & 20 \\
An & 160 & 0 \\
Wo & 160 & 0 \\
$\alpha_{1}$-AT-sufficient (patients with emphysema) \\
Co & 5 & 97 \\
Ne & 60 & 59 \\
Su & 45 & 68 \\
Ti & 15 & 89 \\
Ui & 45 & 72 \\
Ba & 40 & 74 \\
& & \\
& &
\end{tabular}

* Conditions of test: soluble fraction of serum after addition of ammonium sulfate at $45 \%$ saturation, followed by dialysis against phosphate-buffered saline and concentration of soluble fraction of one third the original volume of serum. $20 \mu \mathrm{l}$ serum fraction was incubated with $50 \mu \mathrm{l}$ bacterial factor at $25^{\circ} \mathrm{C}$ for $20 \mathrm{~min}$, followed by dilution in Hanks medium and chemotactic testing. See text. fate at $45 \%$ saturation. The soluble fraction, containing the chemotactic factor inactivator, was dialyzed in phosphate buffered saline, then concentrated with Amicon PM10 membranes (Amicon Corp., Lexington, Mass.) to one-third the original volume of serum. When normal human serum is fractionated, this results in a preparation rich in chemotactic factor inactivator (10). For assay, $20 \mu \mathrm{l}$ inactivator was added to $50 \mu \mathrm{l}$ bacterial chemotactic factor and $100 \mu 1$ phosphate-buffered saline ( $\mathrm{pH} 7.4)$, the mixture incubated at $25^{\circ} \mathrm{C}$ for $20 \mathrm{~min}$, then diluted to $1.0 \mathrm{ml}$ in Hanks medium for chemotactic assay.

\section{RESULTS}

Lack of chemotactic factor inactivator in sera-dficient in $\alpha_{t}$ antitrypsin. When the soluble ammonium sulfate fractions of four normal human sera were incubated with the bacterial chemotactic factor, $70-80 \%$ inhibition of the chemotactic activity resulted (Table I). The loss of activity reflects the action of the chemotactic factor inactivator present in the concentrated fraction of normal serum. The serum fractions from six different patients with chronic, progressive pulmonary emphysema were each found to contain significant inhibitory activity for the chemotactic factor. It was previously determined that in each of these sera there were substantial levels of $\alpha_{1}$-AT (see above). In contrast, in spite of the fact that four different human sera, each deficient in the trypsin inhibitor, were fractionated and concentrated in the same manner, inhibitory activity for the bacterial chemotactic factor was lacking, or present in much lower quantity (Table I). The lack of an immunological assay for the chemotactic factor inactivator has not allowed determination of precise levels of the inactivator in the individual sera. These data indicate that serum deficiencies of the chemotactic factor inactivator are associated with $\alpha_{1}$-AT deficiency, but not with the clinical condition of pulmonary emphysema per se.

In order to determine if $\alpha_{1}$-AT-deficient serum had a blocking effect on the expression of the activity of the chemotactic factor inactivator, $50 \mu 1$ of the chemotactic factor inactivator (prepared from normal serum according to the details listed above) was added to $50 \mu 1$ of normal human serum and to an $\alpha_{1}$-AT-deficient serum. No loss in the ability of the inactivator to inhibit the chemotactic factor was noted in the two sera $(81 \%$ inhibition vs. $85 \%$ inhibition in the normal and the $\alpha_{1}$-AT(leficient serum, respectively). These results suggest that the loss of chemotactic factor inactivator in the $\alpha_{1}$-ATdeficient sera is not due to impairment of an existent inactivator in these sera.

The generation of super-normal amounts of chemotactic activity in inhibitor-deficient sera. Since it is now established that the chemotactic factor inactivator inhibits the complement-derived chemotactic factors (C3 and $\mathrm{C} 5$ fragments, $\mathrm{C} \overline{567})$ as well as the bacterial chemotactic factor (10), it became of interest to determine the 
TABLE II

Generation of Chemotactic Activity in Various Human Sera

Chemotactic activity in serum*

\begin{tabular}{cccc} 
& \multicolumn{3}{c}{ Chemotactic activity in serum* } \\
\cline { 2 - 4 } Serum & $50 \mu \mathrm{l}$ & $25 \mu \mathrm{l}$ & $10 \mu \mathrm{l}$ \\
\hline Normal $\alpha_{1}$-AT & & & \\
1 & 190 & 80 & 20 \\
2 & 95 & 60 & 50 \\
3 & 205 & 70 & 50 \\
4 & 240 & 30 & 40 \\
5 & 160 & 120 & 20 \\
mean $\ddagger$ & $178 \pm 41$ & $72 \pm 22$ & $36 \pm 12$ \\
Deficient $\alpha_{1}$-AT & & \\
6 & 215 & 150 & 130 \\
7 & 205 & 160 & 110 \\
8 & 190 & 160 & 100 \\
9 & 245 & 190 & 100 \\
10 & 220 & 130 & 100 \\
mean & $215 \pm 14$ & $158 \pm 14$ & $108 \pm 9$
\end{tabular}

* $0.1 \mathrm{ml}$ serum incubated $30 \mathrm{~min}$ at $37^{\circ} \mathrm{C}$ with BSA-anti-BSA complex, made at antigen equivalence with $40 \mu \mathrm{g} \mathrm{N}$ antibody Volumes represent equivalence of original serum tested. $\ddagger$ Mean value \pm SEM

amount of chemotactic activity generated in normal sera and in those sera lacking the chemotactic factor inactivator (along with $\alpha_{1}-\mathrm{AT}$ ). This experiment was done in view of the knowledge that when human serum is chemotactically activated, the resulting chemotactic activity is ascribable to C5 products $(13,14)$, these factors being susceptible to the action of the chemotactic factor inactivator derived from normal human serum (10). The data in Table II compare the amounts of chemotactic activity generated in five normal sera and five $\alpha_{1}$-AT-deficient sera after incubation with immune complexes. The amount of chemotactic activity generated in the $\alpha_{1}$-AT-deficient sera is two- to threefold greater than the activity generated in normal ( $\alpha_{1}$-AT-sufficient) human serum. In view of the data in Table I, these findings are not surprising.

\section{DISCUSSION}

It can be concluded from these experiments that those sera deficient in the $\alpha_{1}$-AT are also deficient in the chemotactic factor inactivator. The most obvious possibility to explain such an association would be identity of the two inhibitors. Evidence so far is against this likelihood. Operationally, the two inhibitors work in quite different ways. The $\alpha_{1}$-AT binds to the enzyme in stoichiometric fashion to render it inactive. In studies with the chemotactic factor inactivator, all evidence of binding to the radiotagged $\mathrm{C} 5$ chemotactic fragment has been negative (10). It seems probable that the inactivator of chemo- tactic activity destroys the chemotactic factor in an enzymatic manner, such as kininases destroy kinins (7). A second point that tends to distinguish the two inhibitors is estimates of molecular weight. The $\alpha_{1}-\mathrm{AT}$ has a molecular weight of 45,000 , while estimates of the chemotactic factor inactivator suggest the presence of two inhibitors in serum, which may have molecular weights considerably above or below the figure of 45,000 (10). Whether the chemotactic factor inactivator is or is not identical with $\alpha_{1}$-AT or with the anaphylatoxin inactivator is a minor consideration in the context of this paper. The message of this report is the lack of the chemotactic factor inactivator in sera deficient in $\alpha_{1}$-AT.

The data also suggest that the deficiency of the chemotactic factor inactivator is not associated per se with the condition of pulmonary emphysema, since $\alpha_{1}$-AT-sufficient serum from patients with chronic progressive pulmonary emphysema have substantial levels in the serum of the chemotactic factor inactivator. Further, it appears that the lack of chemotactic factor inactivator in $\alpha_{1}$-AT. deficient serum is an actual loss of the inactivator rather than its impairment.

It has been suggested that a high percentage of patients with deficiency of $\alpha_{1}$-AT develop pulmonary emphysema because the trypsin-like enzymes, including elastase and the neutral proteases derived from lysosomal granules of neutrophilic granulocytes (3), react in an uncontrolled fashion. The data in this paper indicate a second possibility must also be considered: the deficiency or absence of the naturally occurring chemotactic factor inactivator in the serum of the same patients (Table I) could mean an important mechanism for achieving balance of inflammatory responses is missing (Table I). Lacking this control, larger than normal amounts of chemotactic factors would be generated by complementdependent mechanisms (Table II). With more chemotactic factors being generated and with no natural mechanism to inactive these inflammatory mediators, the stage would be set for inordinate delivery of neutrophils (and their enzymes) to inflammatory exudates. The excessive delivery of cells along with the lack of a natural inhibitor to block the action of trypsin-like enzymes from the leukocytes would make for a highly disadvantageous situation. In view of the data presented here, it would seem appropriate to consider modifying the theories of the pathogenesis of pulmonary emphysema in patients who lack $\alpha_{1}$-AT.

\section{ACKNOWLEDGMENTS}

These studies were supported in part by National Institutes of Health Grant AI-09651-02.

\section{REFERENCES}

1. Talamo, R. C. 1971. The $\alpha_{1}$-antitrypsin in man. J. of Allergy and Clin. Immunol. 48: 240. 
2. Kueppers, F., and A. C. Bearn. 1966. A possible experimental approach to the association of hereditary $\alpha_{1}$ antitrypsin deficiency and pulmonary emphysema. Proc. Soc. Exp. Biol. Med. 121: 1207.

3. Janoff, A. 1970. Mediators of tissue damage in leukocyte lysosomes. X. Further studies on human granulocyte elastase. Lab. Invest. 22 : 228.

4. Lieberman, J. 1972. Digestion of antitrypsin-deficient lung by leukoproteases. In Pulmonary Emphysema and Proteolysis. C. Mittman, editor. Academic Press, Inc., New York. 189.

5. Pierce, J., A. Eisen, and H. K. Dhingra. 1969. Pathogenesis of emphysema in antitrypsin deficiency. Clin. Res. $17: 477$.

6. Gans, H., and B. H. Tan. 1967. $\alpha_{1}$-antitrypsin, an inhibitor for thrombin and plasmin. Clin. Chim. Acta. 17: 111.

7. Erdös, E., and H. Y. T. Yang. 1970. Kininases. In Bradykinin, Kallidin and Kallikrein, Handbook of Experimental Pharmacology. E. G. Erdos, editor. Springer Publishing Co. Inc., New York. 289.

8. Müller-Eberhard, H. J., V. A. Bokisch, and D. B. Budzko. 1970. Studies of human anaphylatoxins and of their physiological control mechanism. In Immunopathology, VIth International Symposium (Grindelwald) 1970. P. A. Miescher, editor. Grune and Stratton Inc., New York. 191.
9. Bokisch, V. A., and H. J. Müller-Eberhard. 1970. Anaphylatoxin inactivator of human plasma: its isolation and characterization as a carboxypeptidase. J. Clin. Invest. $49: 2427$.

10. Berenberg, J. L., and P. A. Ward. 1973. The chemotactic factor inactivator in normal human serum. J. Clin. Invest. In press.

11. Talamo. R. C., C. E. Langley, and N. E. Hyslop, Jr. 1972. A comparison of functional and immunochemical measurements of serum alpha ${ }_{1}$-antitrypsin. In Pulmonary Emphysema and Proteolysis. C. Mittman, editor. Academic Press Inc., New York. 167.

12. Fagerhol, M., and C. B. Laurell. 1967. The polymorphism of "prealbumins" and $\alpha_{1}$-antitrypsin in human sera. Clin. Chim. Acta. 16: 199.

13. Ward, P. A., C. G. Cochrane, and H. J. Müller-Eberhard. 1966. The role of serum complement in chemotaxis of leukocytes in vitro. J. Exp. Med. 122: 327.

14. Ward, P. A., C. G. Cochrane, and H. J. Müller-Eberhard. 1966. Further studies on the chemotactic factor of complement and its formation in vivo. Immunology. 11: 141.

15. Ward, P. A., I. H. Lepow, and L. J. Newman. 1968. Bacterial factors chemotactic for polymorphonuclear leukocytes. Am. J. Pathol. 52: 725.

16. Ward, P. A., and C. G. Cochrane. 1965. Bound complement and immunologic vasculitis. J. Exp. Med. 121: 215. 